\title{
A NOTE ON THE POSITION OF THE EYE IN A THIRD NERVE PALSY*
}

\section{BY}

Eugene Wolff and Surgeon Commander Heffernan LONDON

IT is generally stated that in a complete third nerve palsy the eye looks out and somewhat down or simply down and out due to overaction of the external rectus and superior oblique.

We would submit that this statement requires some qualification. The eye is certainly abducted but as in this position the superior oblique cannot depress the eye or only very slightly, the amount of depression is minimal or nil as in the following case :-

On November 18, 1946, G.W., aged 21 years, was involved in a collision while motor cycling.

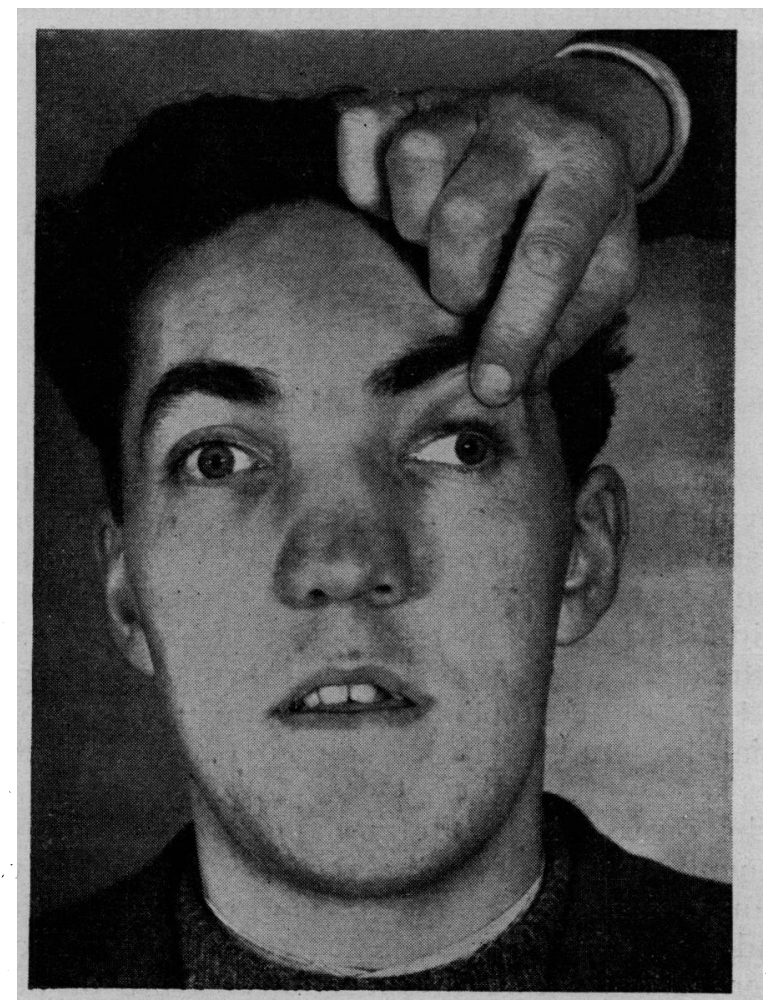

FIG. 1.

* Received for publication, February 27, 1947. 
He was taken to hospital and did not recover consciousness for five days.

When he came to, he noticed that he could not open his left eye. There was no other paralysis but he was told that he had had a temporary left sided hemiplegia for the first three days. He noticed that when he lifted the left upper lid with his hand he saw double, The diagnosis was fracture of base of skull, nasal bones and lett jaw with left-sided third nerve paralysis.

When seen on January 20,1947, we found as follows :-

Left eye closed, but he could lift the lid very slightly with the aid of the frontalis. Vision $6 / 6$ in each eye.

Left pupil larger than right and fixed to light and convergence.

With the right eye looking straight forward and the left lid lifted manually (Fig. 1) the left eye was seen to be directed directly outwards. The corneal reflexes were on the same horizontal level.

On directing his right vision to the extreme right the left eye came to the mid-line. No other movement of the left eye was possible except in-torsion on asking the patient to look down. Both fundi were normal,

\title{
WAREN TAY-SACHS DISEASE IN A CHINESE INFANT*
}

\author{
B Y \\ Gopal Haridas \\ (FROM THE CIVIL GENERAL HOSPITAL, SINGAPORE)
}

A surver of all the available literature on Tay-Sachs disease fails to reveal evidence of the record of a case previously from Malaya. I am thus submitting a full report of a case, which was admitted to the General Hospital, Singapore-the first case of its kind occurring in Malaya in a non-Hebrew infant-together with a brief review of the clinical types, history and symptomatology which I believe will not prove repetitious in spite of the extensive and controversial literature that has already been written on this subject.

Tay-Sachs disease is the infantile form of amaurotic family idiocy. Amaurotic family idiocy is a type of progressive cerebral degeneration which comes under the large group of the cerebroretinal syndromes of the heredo-degenerative type. The following most modern classification of the clinical types of the cerebroretinal syndromes of the heredo-degenerative type is given in the British Encyclopaedia of Medical Practice, Volume III :-

\footnotetext{
- Received for publication, March 29, 1947.
} 